\title{
MODEL 9975 SHIPPING PACKAGE: IMPACT OF CAPLUG REMOVAL ON FIBERBOARD MOISTURE LEVEL
}

\author{
W. L. Daugherty \\ Savannah River National Laboratory \\ Materials Science \& Technology
}

Publication Date: June 2011

Savannah River Nuclear Solutions

\section{Savannah River Site}

Aiken, SC 29808

This document was prepared in conjunction with work accomplished under

Contract No. DE-AC09-08SR22470 with the U.S. Department of Energy. 


\section{DISCLAIMER}

This work was prepared under an agreement with and funded by the U.S. Government. Neither the U. S. Government or its employees, nor any of its contractors, subcontractors or their employees, makes any express or implied: 1. warranty or assumes any legal liability for the accuracy, completeness, or for the use or results of such use of any information, product, or process disclosed; or 2. representation that such use or results of such use would not infringe privately owned rights; or 3. endorsement or recommendation of any specifically identified commercial product, process, or service. Any views and opinions of authors expressed in this work do not necessarily state or reflect those of the United States Government, or its contractors, or subcontractors. 


\section{Model 9975 Shipping Package: Impact of}

\section{Caplug Removal on Fiberboard Moisture Level}

\section{APPROVALS:}

W. L. Daugherty

Date

Author, Materials Science and Technology

T. E. Skidmore

Date

Technical Review, Materials Science and Technology

K. A. Dunn

Date

Pu Surveillance Program Lead, Materials Science and Technology

G. T. Chandler

Date

Manager, Materials App \& Process Tech

E. R. Hackney

Date

NMM Engineering

\section{REVIEWS:}

D. R. LeDuc

Date

Savannah River Packaging Technology 


\title{
Revision Log
}

\begin{abstract}
$\begin{array}{lll}\text { Document No. SRNL-STI-2011-00380 } & \text { Rev. No. } 0\end{array}$
Document Title Model 9975 Shipping Package: Impact of Caplug Removal on Fiberboard Moisture Level
\end{abstract}

Rev. \# Page \# Description of Revision Date

0 all Original document 6/23/2011 


\section{Summary}

Two 9975 shipping packages removed from service in K-Area Complex (KAC) due to an excessive axial gap have been tested in SRNL to determine if caplug removal would facilitate the reduction of excess fiberboard moisture. An additional question to be answered through this testing was whether the resulting moisture loss would reduce the axial gap, reversing the effect seen during storage with excess moisture present.

These packages have completed approximately 1 year in test, during which time the weight of each package has steadily decreased as a result of moisture migration out of the package. However, elevated moisture levels still remain in the packages. During this test period, the bottom fiberboard layers of package 9975-01818 (which contained the greater amount of excess moisture) experienced further compaction, and the axial gap of both packages has increased.

This effort has shown that removal of the caplugs may not be a sufficient measure to rehabilitate packages with excess moisture or excess axial gaps in a timely manner. However, this measure might make a meaningful contribution in combination with other actions (to be determined). It is recommended that the caplug removal tests in SRNL be discontinued at this time.

\section{Background}

Two 9975 shipping packages were removed from KAC and provided to SRNL for test purposes, after both packages were found to exceed the 1 inch maximum criterion for the axial gap at the top of the package [1]. Package 9975-01818 was found with an axial gap of 1.437 inch, and an estimated 2.5 liters of excess moisture in the lower fiberboard layers. Package 9975-02287 was found with an axial gap of 1.008 inch, and only slightly elevated moisture levels relative to typical packages.

Prior data from the 9975 Surveillance Program has shown that the 9975 drum provides a degree of isolation, and will tend to preserve fiberboard moisture levels for an extended period of time [2]. Both packages were provided to SRNL to identify whether removal of the 4 caplugs in each package would allow moisture to escape the package. Following testing with the caplugs removed for approximately 1 year, this report documents the findings from this effort.

\section{Experimental Method}

The fiberboard assemblies from both packages were examined in KAC upon discovery of the axial gap condition. This examination is documented in Reference 3. After receipt of the 2 packages in SRNL, each was re-examined to establish a baseline condition of the fiberboard prior to testing. A modified shield lid, containment vessels and 3013 container were placed in package 9975-01818. A cartridge heater in the 3013 container provided an internal heat source of 5 watts. Wires from the heater and several thermocouples were routed through the shield lid, between the upper and lower fiberboard assemblies and through a caplug hole. Package 997502287 did not contain an internal heat source during testing. Accordingly, its containment vessels remained out of the package (for convenience), although the shield lid was in place to 
maintain a consistent environment for the fiberboard. Both packages had a thermocouple on the drum exterior.

All 4 caplugs were removed from both packages. The packages were weighed weekly to determine how fast moisture within the package can effectively escape through the 4 caplug holes. Periodic weighing has continued for a period slightly greater than 1 year to capture the influence of seasonal variation. Each package has been opened approximately every 15 weeks to characterize the fiberboard. The total time in test has been approximately 60 weeks.

\section{Initial SRNL Characterization:}

Baseline characterization of both packages prior to testing included package weight, and fiberboard weight, dimensions and moisture content. After characterization, the fiberboard assemblies were returned to their packages. The caplugs were removed from the drums at this time, but the caplug holes were taped over from the outside until testing was ready to begin.

The sketch in Figure 1 shows the approximate placement of a heater in a 3013 container, which is loaded with steel shot. This 3013 container, along with a modified SCV and PCV, have been previously used in the 9975 life extension program. The SCV and PCV were closed, but did not contain O-ring seals. They were placed in the shield of package 9975-01818, and the instrumentation wires routed through a hole in a modified shield lid (available from previous activities), around the upper fiberboard assembly, and out through a caplug hole. An additional thermocouple was placed between the lower fiberboard and drum, and its wire also exited the caplug hole. One final thermocouple was attached to the drum exterior to monitor variation in the ambient condition. The internal heater for package 9975-01818 was set for a constant heat output of $5 \mathrm{~W}$.

Package 9975-02287 was tested in the as-received condition, with no internal heat source. One thermocouple was attached to the drum exterior to monitor the ambient condition.

Testing of both packages occurred in 773-A, D-0189 (Fab Lab). This space has nominal climate control, but experiences some temperature and humidity variation on a daily and seasonal basis. The ambient temperature and humidity have been recorded daily throughout this testing.

\section{Periodic Measurements:}

On an approximately weekly basis, each package has been weighed, and the relative humidity in the air space over the upper fiberboard assembly recorded. The ambient humidity is also recorded for comparison.

Approximately once every 3 months, the packages have been opened and the fiberboard assemblies re-characterized. The packages are weighed before and after opening to identify any weight change related to that activity.

\section{$\underline{\text { Results }}$}

Temperatures of each package are compared to ambient conditions in Figure 2. The drum surface temperature of each package remained close to the ambient laboratory temperature, as 
would be expected. The heated 3013 inside 9975-01818 maintained an internal temperature approximately $25-30{ }^{\circ} \mathrm{F}$ higher than ambient. The humidity within the air space at the top of each package varied with the ambient humidity, and was generally slightly greater than the ambient humidity. This difference was more pronounced in 9975-01818 than in 9975-02287, as seen in Figure 3.

Figure 3 also shows that 9975-01818 lost weight continuously throughout the test period. The rate of weight loss was varied, with higher rates during the winter and lower rates in the summer. A small but pronounced weight loss occurred each time the package was opened for examination. Package 9975-02287 also lost weight throughout the test period, but experienced two brief periods of constant weight. These periods occurred during mid-summer, and again the following spring (at the end of the test period). The weight of 9975-02287 generally did not change significantly during the periodic examinations.

The fiberboard moisture content was measured during the baseline and periodic examinations. These data are summarized in Tables 1 and 2. Despite the fact that 9975-02287 lost weight throughout the test period, the fiberboard moisture readings during the first periodic inspection indicate an overall increase over the baseline moisture readings. Subsequent readings decreased until the last inspection, when most locations again showed a slight increase in moisture content. In 9975-01818, the inner diameter surfaces experienced an initial decrease in moisture content, while the outer surfaces got moister. After this initial re-distribution, the moisture content of 9975-01818 steadily decreased until the last inspection period when some areas showed a slight increase in moisture content (although the weight continued to decrease).

\section{$\underline{\text { Discussion }}$}

The humidity inside the package (within the top air space) increases when the room humidity increases, and the humidity within the packages is generally a little higher than the room humidity. The rate of weight loss for each package varies somewhat, but generally varies inversely with humidity. Greater weight loss rates generally occurred in the winter when the ambient humidity is less. If removing the caplugs from packages in storage were to be considered as a means to reduce the moisture content of a significant number of packages, the additional implementation of a means to reduce the ambient humidity within the facility would be desirable.

Between the time 9975-01818 was examined in KAC and its receipt in SRNL for testing, the total fiberboard height increased by 0.030 inch. However, this increase was not uniform at all elevations of the fiberboard assembly. The bottom region (below the lower assembly bearing plate) decreased in height by 0.155 inch, while the remainder of the lower assembly increased in height by 0.081 inch. The upper assembly increased in height by 0.104 inch. Similarly, package 9975-02287 experienced a fiberboard height increase of 0.026 inch, while the bottom layers decreased by 0.078 inch between the time it was examined in KAC and received in SRNL. For this package, the remainder of the lower assembly remained essentially unchanged while the upper assembly increased in height by 0.102 inch. 
Note that these measurements indicate a net increase in fiberboard height between the examination in KAC and the baseline SRNL inspection, while they also show the axial gap at the top of each package increased. This apparent inconsistency likely results from a difference in measurement technique. The measurements were made by the same individual on both occasions (KAC and baseline SRNL). However, the calipers available in KAC were not large enough to measure the overall height of the lower fiberboard assembly (26.7 inches nominal), so this dimension was obtained from a tape measure, read to the nearest 1/16 inch. In addition, the curvature of the bottom of the lower assembly (molded to the dished drum bottom) adds a source of variability even with the same measurement tool. For both packages, the height decrease in the bottom layers is sufficiently large (compared to the measurement uncertainties) to indicate a real reduction in height, and likely represents compaction of the bottom fiberboard layers due to the dynamic loadings during transport to SRNL. Changes in fiberboard dimensions for both packages are summarized in Table 3. Height changes for each fiberboard assembly are plotted in Figure 4, while changes in the calculated density are shown in Figure 5.

During testing, both packages experienced a continuing decrease in fiberboard height. For 997501818, all regions of the fiberboard (upper assembly, upper portion of lower assembly and bottom layers below the bearing plate) lost height during each inspection interval. Although the bottom layers account for $\sim 11 \%$ of the total fiberboard height, this region experienced $34 \%$ of the height decrease in package 9975-01818. These bottom layers remained saturated with water throughout the test period, and likely experienced continued compaction. In package 997502287, the bottom fiberboard layers below the bearing plate varied in height, with a modest net increase over the test period. The rest of the 9975-02287 fiberboard experienced a steady decrease in height, although the upper assembly increased slightly during the last inspection interval.

Both packages were originally segregated in KAC after identification that the axial gap at the top of the package exceeded 1 inch. This condition remained throughout the testing, with the axial gap increasing in each package. This is consistent with the decrease in fiberboard height for both packages.

It is assumed that any weight change is the result of moisture loss from the fiberboard. Figure 6 compares the change in package weight with the change in fiberboard weight. The 9975-01818 fiberboard lost more weight than indicated by the package weight loss. During the most recent examination of this package, a small amount of water was observed in the bottom of the drum. Varying amounts of liquid in the drum could have contributed to inconsistencies in the fiberboard and drum weight changes.

Package 9975-01818 was previously estimated to contain $\sim 2.5$ liters of excess water beyond that typically found in fiberboard [3]. During this test, it lost weight at a rate of $\sim 860 \mathrm{~g} /$ year. If the weight decreases that occurred during package examinations are ignored, then this package lost weight at an average rate of $\sim 760 \mathrm{~g} /$ year. This rate is indicative of what might occur in storage if the caplugs were removed and the package was otherwise undisturbed. If this rate continued, approximately 3.3 years would be needed to lose all the excess water. However, it is expected that the rate of moisture loss will decrease as the amount of excess water decreases. This effect 
is seen by comparing the rate of weight loss at the beginning of the test (120 g over 48 days) with that 1 year later (84 g over 49 days).

The decreasing rate of weight loss likely reflects largely on the decreasing amount of excess moisture present. Assuming this is the primary reason for rate change, future weight losses can be forecast. The rate of weight loss for package 9975-01818 decreased 30\% after the first year of testing. If this relative decrease is projected to continue (i.e. each year the rate decreases an additional 30\%), the projected total weight losses are shown in Figure 7 for a period of 12 years. After this time, the total weight loss has reached an asymptotic value of $\sim 2545 \mathrm{~g}$. This is surprisingly similar to the original estimate of $\sim 2500 \mathrm{~g}$ of excess moisture present.

Package 9975-02287 was estimated to contain only slightly elevated moisture levels, although an actual amount was not quantified. In contrast to 9975-01818, this package experienced a much lower rate of weight loss -205 g/year. If the weight losses during examinations are ignored, the rate of weight loss for 9975-02287 decreases to $192 \mathrm{~g} /$ year. The initial weight loss rate for 9975-02287 dropped from 40 g over 48 days to 18 g over 49 days, one year later.

The rate of weight loss for package 9975-02287 decreased 55\% over the first year. If future weight losses for this package are projected as was done for 9975-01818, an asymptotic total weight loss of $\sim 360 \mathrm{~g}$ would be reached after $\sim 6$ years.

Before these projections are used to predict the actual behavior of packages stored in KAC, consider that another phenomenon may also contribute to the behavior observed in this test. The moisture level in the bottom fiberboard layers tended to increase over the first few months as moisture within each package redistributed somewhat. With the caplug holes located near the top of the drum, moisture in the higher regions of the fiberboard (at least up to the elevation of the air shield) would escape the package more efficiently than moisture in the bottom layers. To the extent an internal heat load tends to drive moisture to the cooler regions of the package, a warmer zone in the middle fiberboard elevations could help to maintain a degree of separation between excess moisture at the bottom and the caplug holes. This effect is suggested in Figure 6, where most of the 9975-01818 fiberboard weight loss occurs in the upper assembly, even though the upper assembly comprises only 32\% of the fiberboard weight. For 9975-02287, the upper and lower assemblies lose weight at an equal rate for the first 30 weeks, after which most of the additional weight loss comes from the lower assembly.

Both packages have exhibited a moderate loss of weight during the test, but both still retain much of the excess moisture present. The loss in fiberboard height observed for both packages likely reflects a combination of moisture decrease throughout the fiberboard (causing shrinkage) and the retention of significant elevated moisture levels in the bottom fiberboard layers (allowing continued compaction of those layers). This also led to the continuing increase in axial gap observed in both packages.

The excess moisture in package 9975-01818 was concentrated mostly in the bottom fiberboard layers, which showed no decrease in moisture readings during the testing. Note, however, that the moisture meter does not provide a linear response above $40 \% \mathrm{WME}$. Above $40 \% \mathrm{WME}$, the fiberboard fibers are saturated, and relatively little additional water is needed to produce a 
response of $100 \% \mathrm{WME}$. In parallel to the overall weight decreases (moisture loss) that were observed, the fiberboard continued to lose height, as the axial gap increased. Therefore, while removal of the caplugs has helped reduce the excess moisture present, it has not yet improved the nonconforming condition of excess axial gap.

Parallel testing on the dynamic compaction of fiberboard [4, 5] provides two observations that might relate to the test packages. These samples, tested under dynamic loading with varying moisture content, indicate some springback of compacted fiberboard can be expected after the load is removed. While this is a beneficial change, the bottom fiberboard layers in a package in storage will remain under constant load for the entire storage period. The second observation from the dynamic compaction testing shows that fiberboard remaining under constant load will vary in height as its moisture level changes - as fiberboard with elevated moisture dries out, part of the compressed height recovers. This second observation would be relevant to packages in storage, but this trend is not seen clearly in the two caplug removal packages. In the case of 9975-01818, the moisture level of the bottom layers is much higher than examined in the dynamic compaction tests (100\%WME vs $6-35 \% \mathrm{WME})$ and insufficient moisture loss has likely occurred to allow compressed height recovery. In the case of 9975-02287, some variation in height of the bottom layers was observed. However, it did not follow a clear trend with variation in the moisture content of those layers, so the extent to which this phenomenon occurs in a full-scale package is unclear.

It is recommended that the caplug removal tests be terminated at this point. They have demonstrated that the loss of excess moisture is facilitated by removing the caplugs. However, significant periods of time are required to accomplish this, and an excess axial gap may not be reduced by this process. Any heat load within the package may contribute to the continued segregation of moisture toward the bottom of the package and reduce the rate of moisture loss. While the package remains in storage, the weight on the bottom fiberboard layers (from the shield, containment vessel and payload) remains in place, and springback of compacted fiberboard will be minimal.

\section{$\underline{\text { Conclusions }}$}

Two 9975 shipping packages removed from service in KAC due to an excessive axial gap have been tested in SRNL to determine if removing their caplugs would facilitate the reduction of excess moisture in the fiberboard and reduce the axial gap. After 1 year in test, approximately $30-35 \%$ of the excess moisture estimated to be present has been removed from these packages, however, a significant amount (65-70\%) of the excess moisture remains and the axial gap has increased. This effort has shown that removal of the caplugs may not be a sufficient measure to rehabilitate packages with excess moisture or excess axial gaps in a timely manner. However, this measure might make a meaningful contribution in combination with other actions (to be determined).

It is recommended that the caplug removal tests be discontinued at this time. 


\section{References}

[1] SRNL-TR-2010-00044, "Task Technical \& Quality Assurance Plan for Testing of Moisture Effects on Model 9975 Package”, T. M. Stefek and W. L. Daugherty, March 2010

[2] PVP2010-25087, "Effects of Moisture in the 9975 Shipping Package Fiberboard Assembly”, W. L. Daugherty, K. A. Dunn, J. L. Murphy and E. R. Hackney, Proceedings of the 2010 Pressure Vessels \& Piping Division / K PVP Conference, PVP2010, July 1822, 2010

[3] SRNL-STI-2009-00742, "Examination of Shipping Packages 9975-01818, 9975-01903 and 9975-02287”, W. L. Daugherty, November 2009

[4] SRNL-STI-2010-00322, "Compaction of Fiberboard Overpack Materials in a 9975 Shipping Package”, T. M. Stefek, W. L. Daugherty, E. G. Estochen and J. L. Murphy, Proceedings $51^{\text {st }}$ INMM Annual Meeting, July 2010.

[5] SRNL-STI-2011-00023, "Compaction of Fiberboard in a 9975 Shipping Package”, T. M. Stefek, W. L. Daugherty, E. G. Estochen and D. R. Leduc, submitted for publication in proceedings of $52^{\text {nd }}$ INMM Annual Meeting, July 17-21, 2011. 
Table 1. Fiberboard moisture measurements for 9975-01818

\begin{tabular}{|l|l|l|l|l|l|}
\hline \multicolumn{5}{|l|}{ Fiberboard moisture content (\%WME) after: } \\
\hline Position & Baseline & 16 wks & 30 wks & 46 wks & 59 wks \\
\hline U1 & 16.9 & 14.7 & 13.1 & 12.3 & 12.3 \\
\hline U2 & 18.0 & 14.2 & 12.4 & 12.3 & 12.9 \\
\hline U3 & 15.3 & 17.6 & 14.9 & 14.2 & 14.2 \\
\hline U4 & 19.1 & 21.6 & 16.6 & 16.5 & 16.9 \\
\hline U5 & 20.9 & 23.6 & 17.9 & 17.4 & 17.8 \\
\hline U6 & 19.5 & 25.0 & 19.4 & 16.0 & 16.6 \\
\hline U7 & 20.2 & 22.1 & 19.9 & 15.9 & 17.3 \\
\hline U8 & 16.0 & 17.0 & 14.6 & 14.2 & 15.0 \\
\hline U9 & 17.7 & 15.1 & 13.8 & 12.4 & 12.7 \\
\hline U10 & 16.5 & 14.3 & 12.7 & 11.5 & 12.5 \\
\hline & & & & & \\
\hline L1 & 22.8 & 14.2 & 13.8 & 13.4 & 14.3 \\
\hline L2 & 20.4 & 16.0 & 14.2 & 14.1 & 14.2 \\
\hline L3 & 17.3 & 15.4 & 12.5 & 13.6 & 13.0 \\
\hline L4 & 17.5 & 20.6 & 15.4 & 14.2 & 14.4 \\
\hline L5 & 19.1 & 21.3 & 17.8 & 16.0 & 15.6 \\
\hline L6 & 21.2 & 23.8 & 20.1 & 18.2 & 18.7 \\
\hline L7 & 21.5 & 45 & 29.2 & 22.9 & 30 \\
\hline L8 & 22.3 & 38 & 41 & 42 & 29.2 \\
\hline L9 & 54 & 100 & 100 & 100 & 100 \\
\hline L10 & 59 & 100 & 100 & 100 & 100 \\
\hline L11 & 34 & 100 & 100 & 96 & 100 \\
\hline L12 & 81 & 100 & 100 & 100 & 100 \\
\hline L13 & 66 & 100 & 100 & 100 & 100 \\
\hline L14 & 22.5 & 41 & 41 & 43 & 41 \\
\hline L15 & 21.4 & 32 & 29.1 & 28.3 & 22.7 \\
\hline L16 & 20.7 & 22.1 & 21.1 & 15.7 & 18.6 \\
\hline L17 & 19.2 & 20.2 & 19.1 & 15.2 & 16.0 \\
\hline L18 & 16.6 & 17.4 & 15.5 & 13.7 & 14.0 \\
\hline L19 & 18.5 & 15.1 & 13.1 & 10.9 & 12.4 \\
\hline L20 & 21.2 & 15.9 & 15.2 & 14.9 & 15.3 \\
\hline L21 & 24.0 & 14.9 & 13.8 & 13.3 & 13.8 \\
\hline & & & & & \\
\hline & & & & & \\
\hline
\end{tabular}
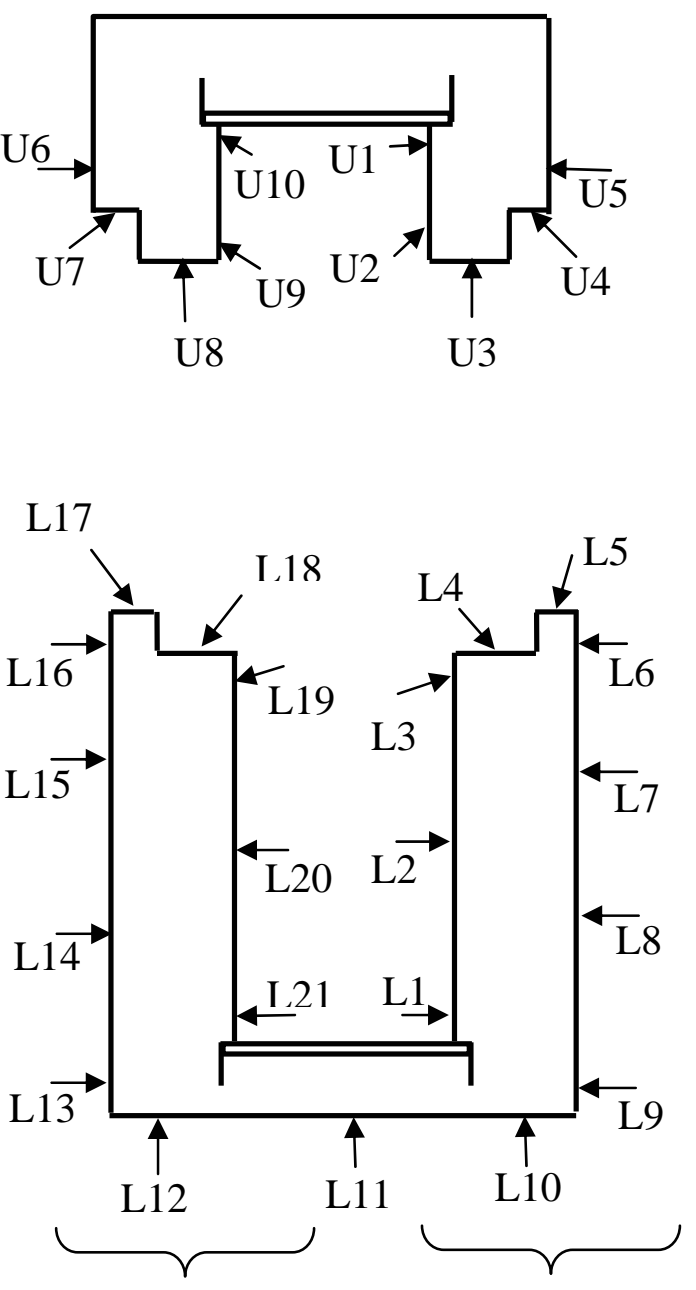

Data@180 deg. Data@0 deg. 
Table 2. Fiberboard moisture measurements for 9975-02287

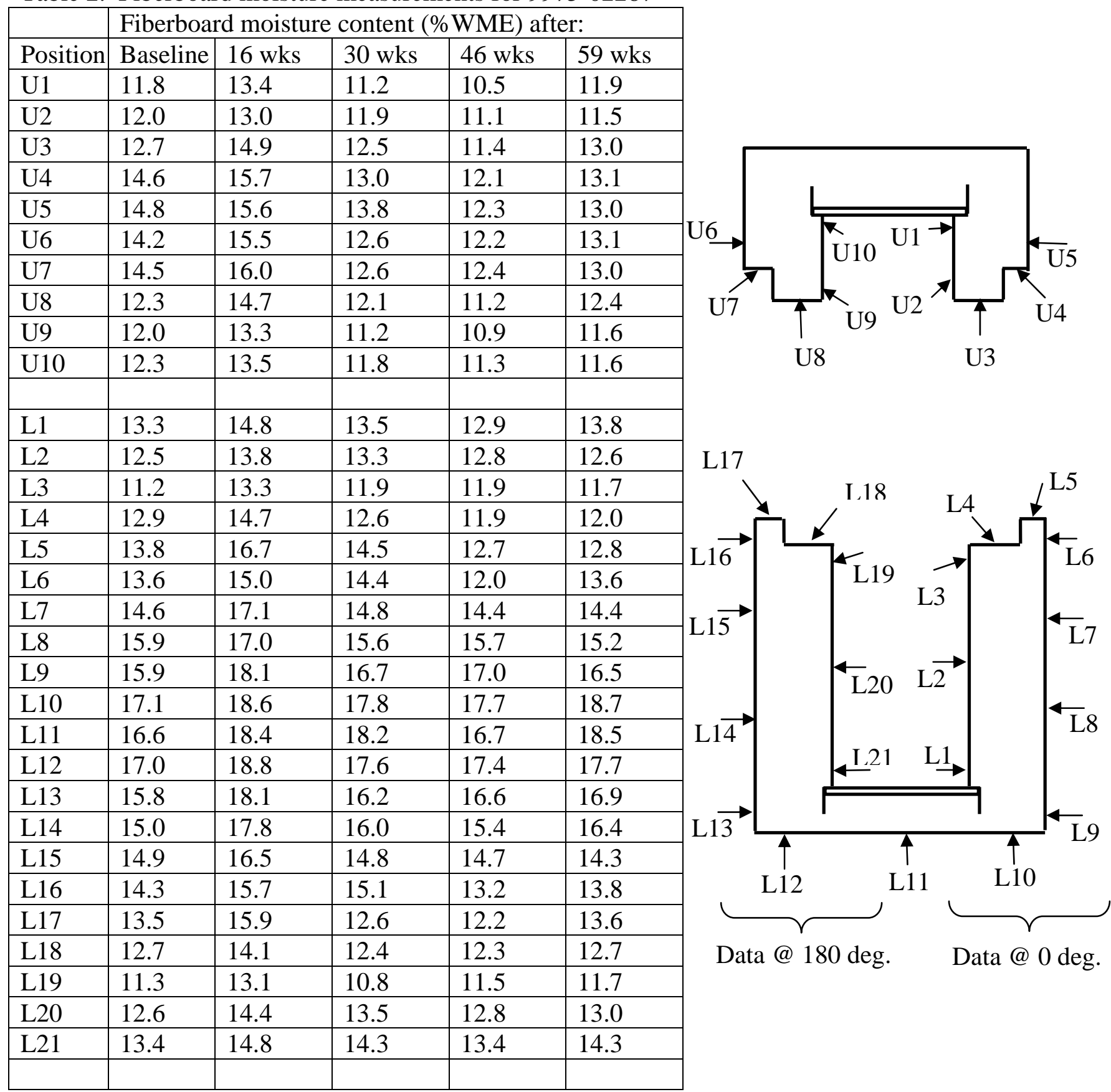


Table 3. Dimensional data relative to fiberboard height

\begin{tabular}{|c|c|c|c|c|c|}
\hline Date & $\begin{array}{l}\text { Days in } \\
\text { Test }\end{array}$ & $\begin{array}{l}\text { Upper } \\
\text { Assy } \\
\text { Height } \\
\text { (inch) }\end{array}$ & $\begin{array}{l}\text { Lower Assy } \\
\text { Height Above } \\
\text { Bearing Plate }{ }^{1} \\
\text { (inch) }\end{array}$ & $\begin{array}{l}\text { Lower Assy } \\
\text { Height Below } \\
\text { Bearing Plate }{ }^{2} \\
\text { (inch) }\end{array}$ & $\begin{array}{l}\text { Axial } \\
\text { Gap } \\
\text { (inch) }\end{array}$ \\
\hline \multicolumn{6}{|c|}{ 9975-01818 } \\
\hline $10 / 26 / 2009$ & 3 & 9.161 & 20.385 & 3.667 & 1.437 \\
\hline $2 / 17 / 2010$ & 4 & 9.265 & 20.466 & 3.512 & 1.508 \\
\hline $7 / 28 / 2010$ & 115 & 9.242 & 20.463 & 3.462 & 1.589 \\
\hline $11 / 3 / 2010$ & 213 & 9.178 & 20.420 & 3.461 & 1.667 \\
\hline $2 / 22 / 2011$ & 324 & 9.163 & 20.390 & 3.457 & 1.784 \\
\hline $5 / 25 / 2011$ & 416 & 9.136 & 20.377 & 3.397 & 1.789 \\
\hline \multicolumn{6}{|c|}{ 9975-02287 } \\
\hline $10 / 26 / 2009$ & 3 & 9.151 & 20.355 & 4.246 & 1.008 \\
\hline $2 / 17 / 2010$ & 4 & 9.253 & 20.357 & 4.168 & 1.028 \\
\hline $7 / 28 / 2010$ & 115 & 9.239 & 20.353 & 4.186 & 1.026 \\
\hline $11 / 3 / 2010$ & 213 & 9.213 & 20.331 & 4.178 & 1.067 \\
\hline $2 / 22 / 2011$ & 324 & 9.208 & 20.318 & 4.169 & 1.099 \\
\hline $5 / 26 / 2011$ & 417 & 9.224 & 20.313 & 4.185 & 1.113 \\
\hline
\end{tabular}

${ }^{1}$ Measured from the inside step on the lower assembly to the top of the bearing plate

${ }^{2}$ Measured from the top of the bearing plate to the bottom of the assembly

${ }^{3}$ Assembly characterized in KAC [1]

${ }^{4}$ Baseline characterization in SRNL. Caplugs were removed and packages began testing on 4/18/2010. 


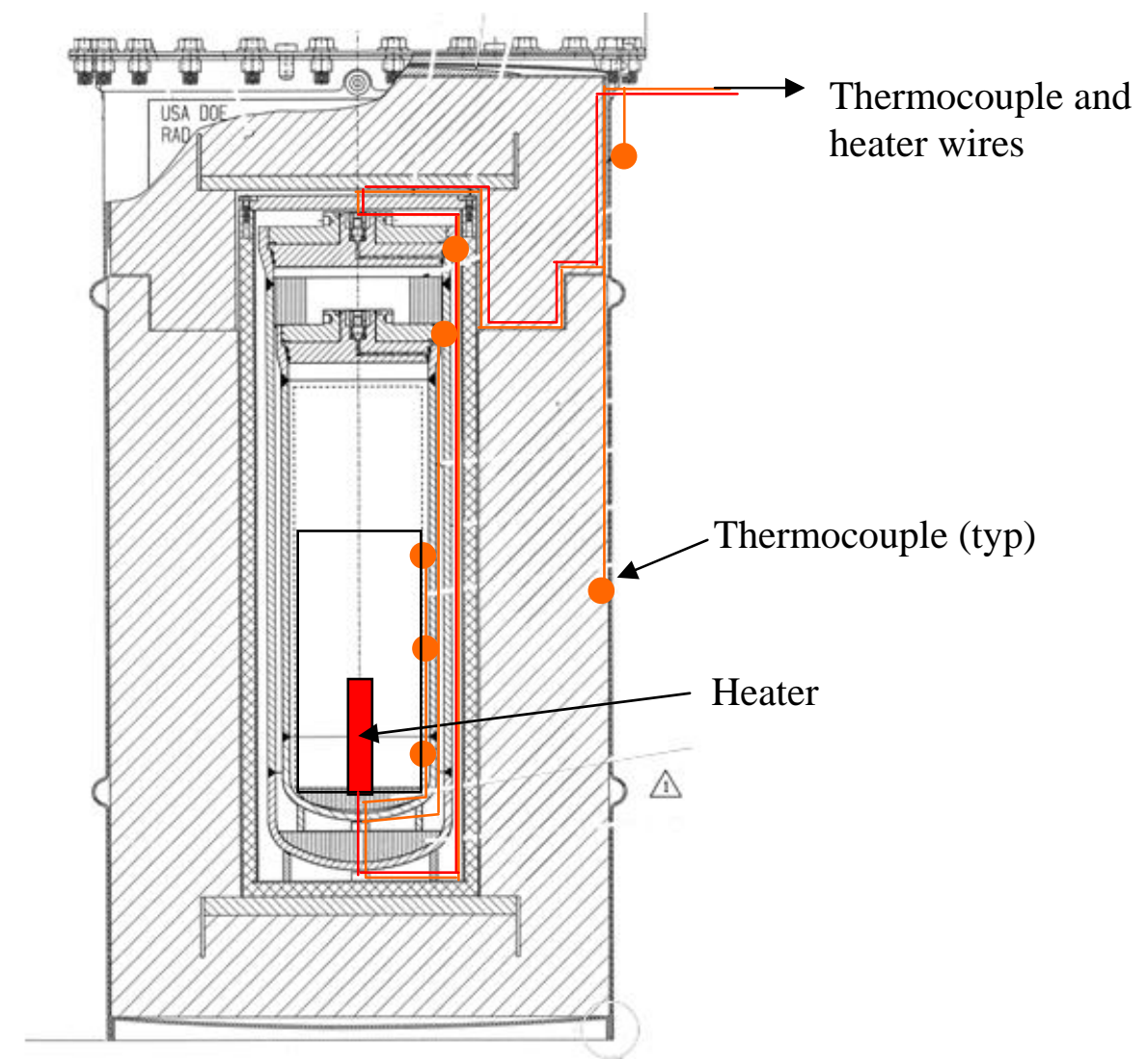

Figure 1. Modifications made to package 9975-01818. The modified PCV, SCV and shield lid from other activities were used instead of modifying the components from this package.

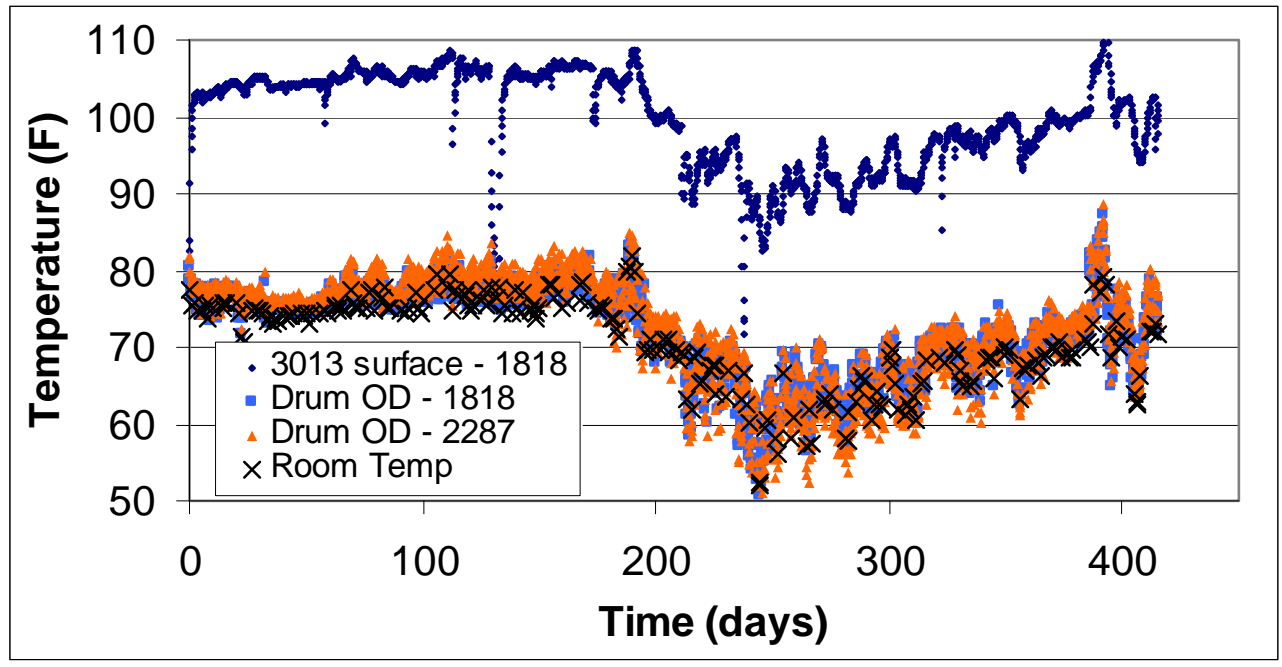

Figure 2. Temperature data from the two test packages compared to room ambient temperature. 


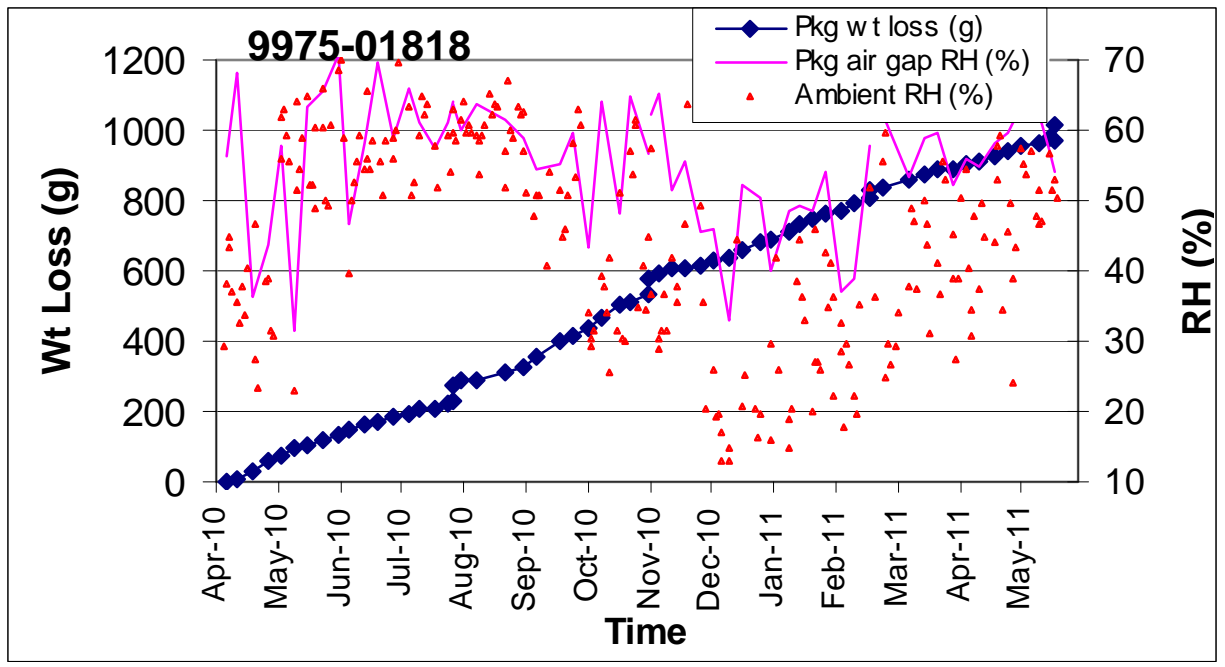

Figure 3.

Humidity data

for the air gap in each package compared to room ambient humidity. Also shown is the weight loss for each package.

(a) $9975-01818$

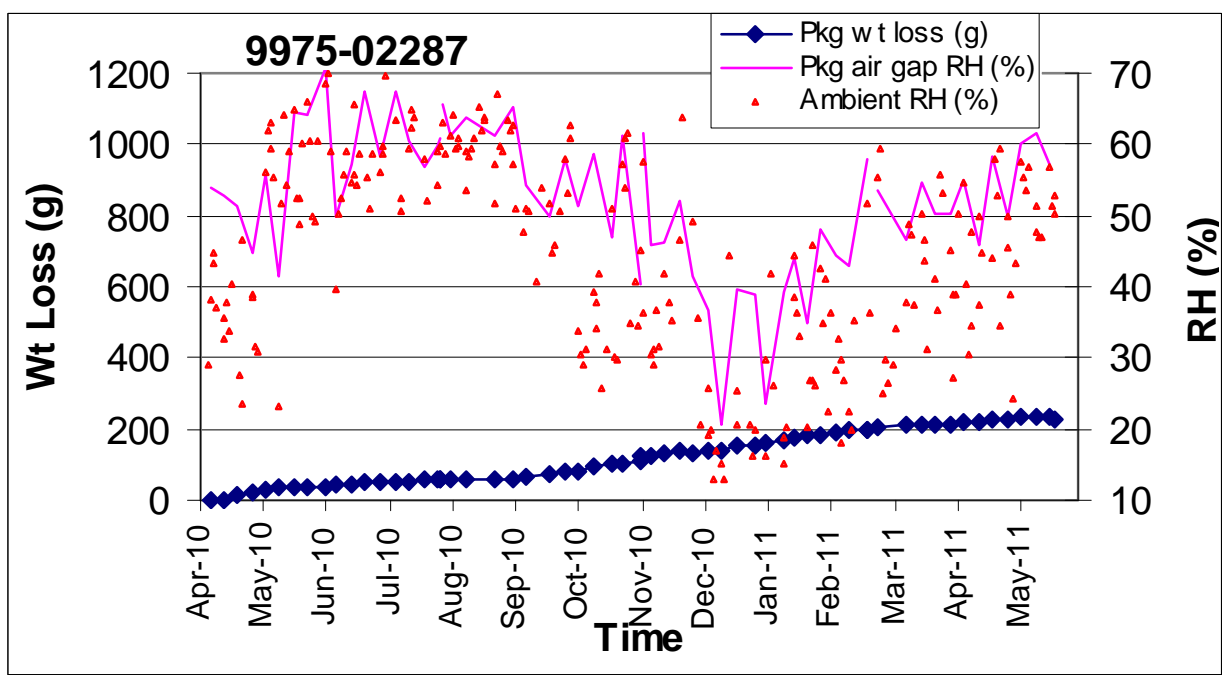

(b) $9975-02287$

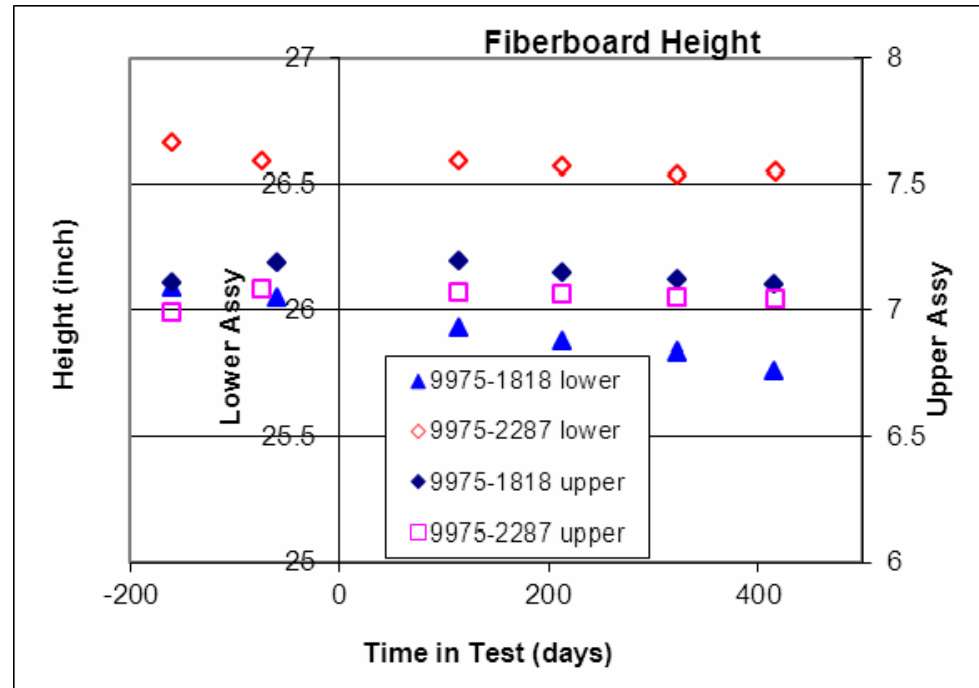

Figure 4. Change in height of each fiberboard assembly. 


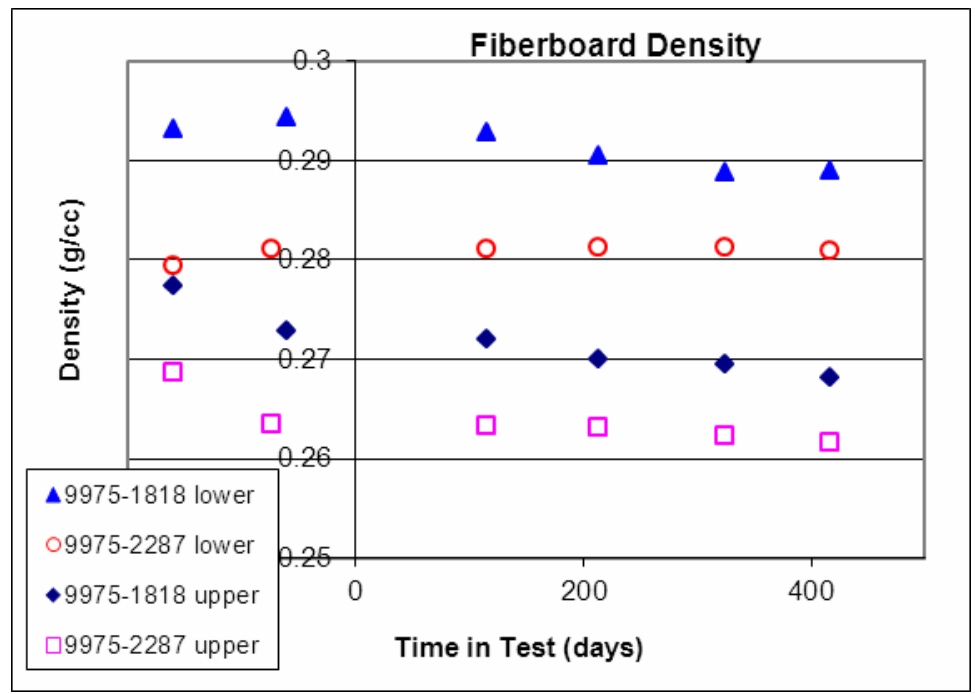

Figure 5. Change in calculated fiberboard density of each fiberboard assembly.

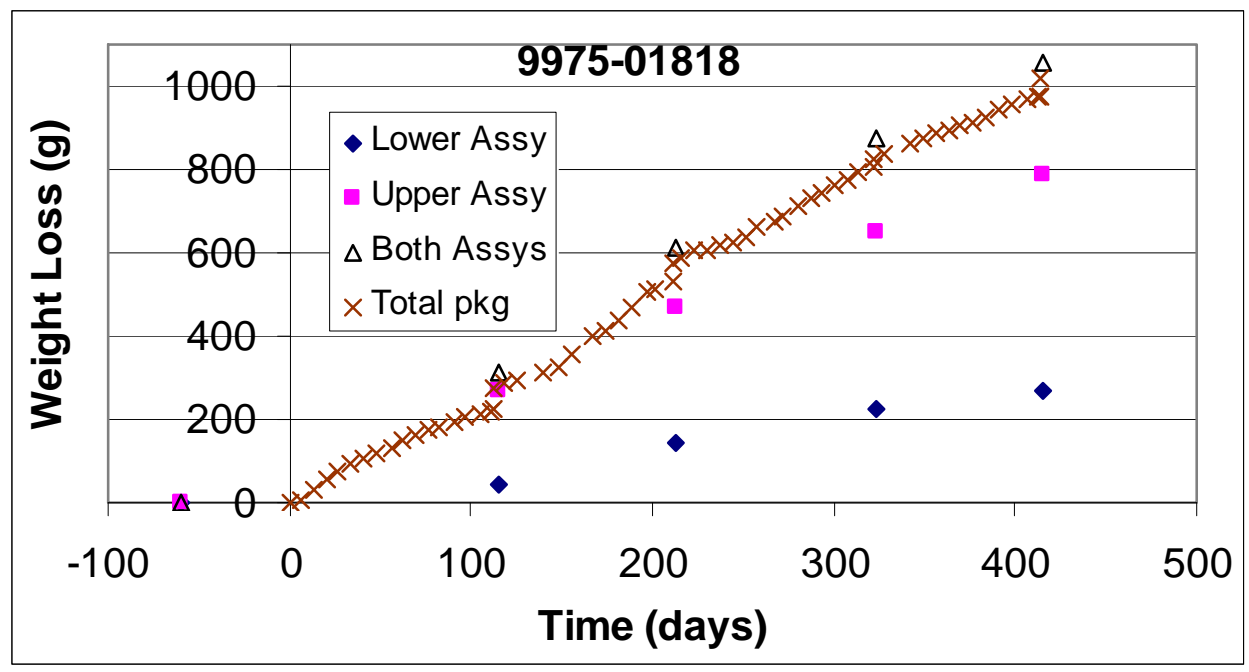

Figure 6.

Weight loss for the two packages compared to weight loss for the fiberboard assemblies.

(a) $9975-01818$

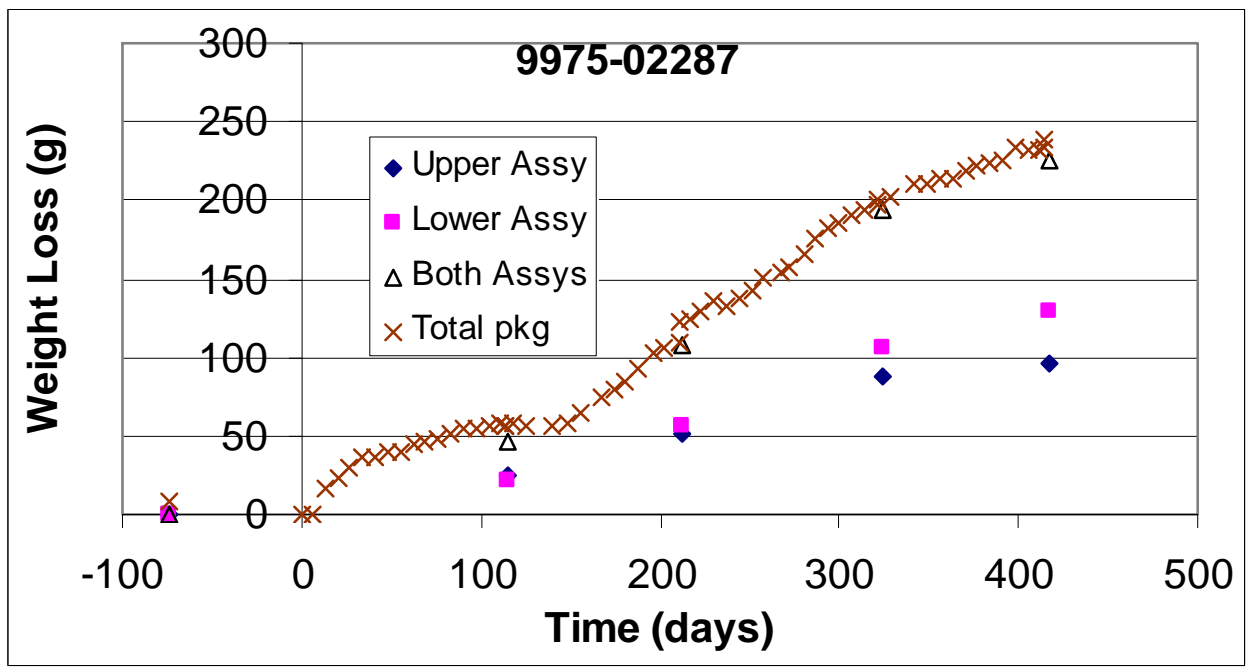

(b) $9975-02287$ 


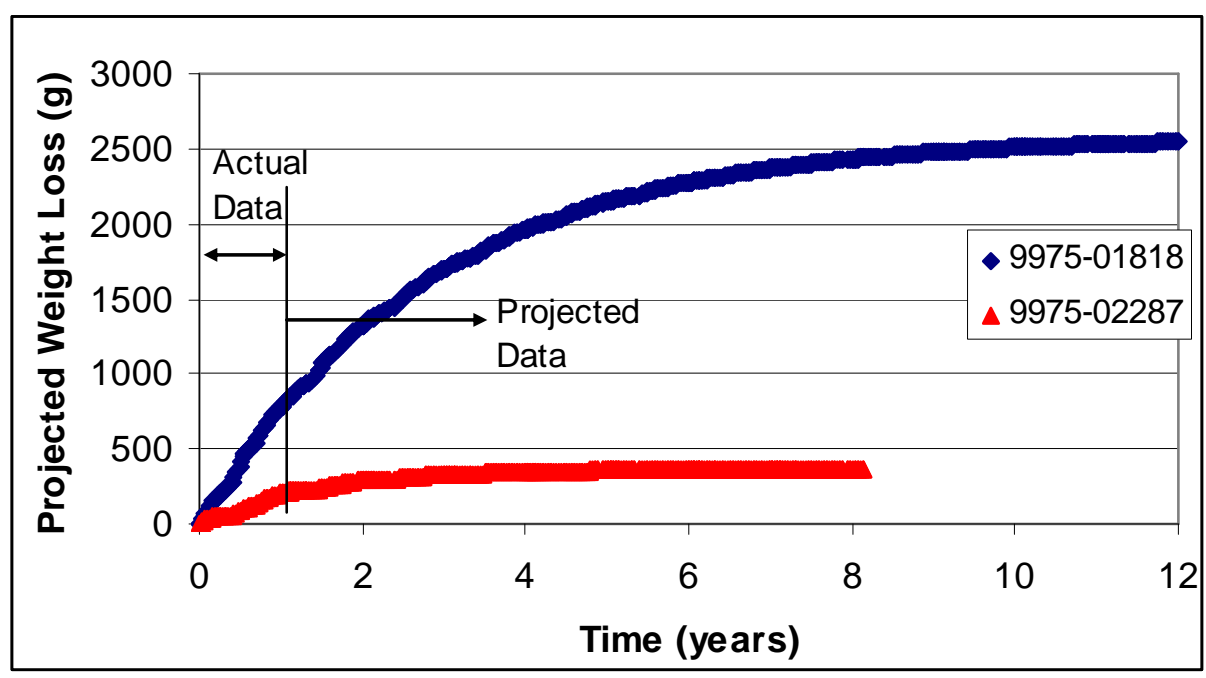

Figure 7. Actual weight loss data for each package (shown in the first 1.13 years) projected to asymptotic values, indicative of the potential for total moisture loss. 
CC: J. S. Bellamy, 773-41A G. T. Chandler, 773-A

W. L. Daugherty, 773-A

K. A. Dunn, 773-41A

B. A. Eberhard, 105-K

E. R. Hackney, 705-K

M. K. Hackney, 705-K

N. C. Iyer, 773-41A

D. R. LeDuc, 773-41A

J. W. McClard, 705-K

J. W. McEvoy, 730-4B

D. L. Melvin, 705-K

T. M. Monahon, 705-K

A. C. Rudy, 705-H

T. E. Skidmore, 730-A

A. J. Stapf, 717-K

Document Control 